\title{
The prevalence of osteoarthritic symptoms of the hands amongst female massage therapists
}

\author{
Heinmari Kruger ${ }^{a}$, Valencia Khumalo ${ }^{a}$, Nicolette Nadene Houreld ${ }^{b}$ * \\ a Department of Somatology, Faculty of Health Sciences, University of Johannesburg, P.O. Box 17011, Doornfontein, \\ 2028, South Africa \\ ${ }^{\mathrm{b}}$ Laser Research Centre, Faculty of Health Sciences, University of Johannesburg, P.O. Box 17011, Doornfontein, 2028, \\ South Africa
}

\section{A R T I C L E I N F O}

Article history:

Received 19 March 2015

Accepted 16 January 2017

\section{Keywords:}

Osteoarthritis

AUSCAN 3.1 Osteoarthritis Index

Questionnaire

Massage

Somatology

Therapist

Occupation

\begin{abstract}
A B S T R A C T
Background: Numerous occupations increase one's risk of developing osteoarthritis. Massage therapists rely heavily on their hands and cumulative hand strain injuries that occur whilst performing a massage may lead to the development of osteoarthritic symptoms. Females are at greater risk of developing osteoarthritis. Furthermore age weight, genetic predisposition; working years, working hours as well as body mass index all increase the risk of developing osteoarthritis.

Objective: This study sought to investigate the prevalence of osteoarthritic symptoms of the hands amongst female massage therapists, as well as to establish both an average age of symptomatic onset and whether their daily work productivity was influenced.

Materials and methods: Since the massage industry is predominantly practiced by females, female massage therapists, irrespective of age and registered with a South African Regulating Body were included. Participants were required to complete a self-administered questionnaire which evaluated age, self-reported symptomatic presence of and family history of osteoarthritis, and body mass index. Participants also completed the AUSCAN"M Hand Osteoarthritis Index LK3.1 (Australian/Canadian Hand Osteoarthritis Index) which assesses pain, disability and joint stiffness of the hands. The sample was divided into two groups based on the presence or absence of self-reported symptoms. All gathered data was analysed by the University of Johannesburg's statistics department (Statkon) by use of IBM SPSS Statistics software version 21.

Results: The mean age of symptomatic presentation was 43 years. The AUSCAN ${ }^{\mathrm{TM}}$ Index found that more than half of the total sample reported osteoarthritic symptoms in their hands. Participants in the non-symptomatic group also indicated a positive response to symptoms on the AUSCAN ${ }^{\mathrm{TM}}$ Index although they did not self-report a symptomatic onset age.
\end{abstract}

\footnotetext{
* Corresponding author. Fax: +27 115596558.

E-mail addresses: heinmari@mweb.co.za (H. Kruger), vkhumalo@uj.ac.za (V. Khumalo), nhoureld@uj.ac.za (N.N. Houreld). Peer review under responsibility of Johannesburg University. 
Conclusion: In this sample, massage therapists experienced osteoarthritic symptoms that cause pain and stiffness in their hands. It also seemed evident that the symptoms experienced were also responsible for placing strain on their ability to perform daily tasks. This study serves as a basis for further dialogue, research and professional awareness.

() 2017 The Authors. Publishing services by Elsevier B.V. on behalf of Johannesburg University. This is an open access article under the CC BY-NC-ND license (http:// creativecommons.org/licenses/by-nc-nd/4.0/).

\section{Introduction}

Massage therapy is an age old practice that has evolved with time and with passing trends, and may be dated back to the ancient Roman, Greek and Egyptian dynasties (Braun \& Simonson, 2008, pp. 2-3). A massage therapist is defined as one who treats clients by using touch to manipulate soft-tissue and muscles within the body. The touch relieves pain, helps to rehabilitate injuries, improves blood and lymph circulation, relieve stress and aids in general relaxation (Bureau of Labour Statistics 2014). Massage once formed a significant part of mainstream medical and nursing occupations, forming an important part of physiotherapy (Casanelia \& Stelfox, 2010). To this day numerous occupations still incorporate various aspects of massage. Massage has a wide variety of applications and is a versatile therapy (Casanelia \& Stelfox, 2010).

Associated Bodywork \& Massage Professionals (ABMP), an American body, commissions a nationwide survey of massage clients every two years. The most recent was conducted by Harstad Strategic Research in January 2013, and surveyed a representative sample of American adults on their use of massage during 2012. Sixteen percent of all American adults visited a massage therapist in 2012 and a further 37\% have visited a massage therapist at some point in their lives. Twenty two percent of adult women and $10 \%$ of adult men visited a massage therapist in 2012. The majority (60\%) of massage clients was female (Patrick, 2014). Seventy percent of clients visited a massage therapist to achieve relaxation and restoration while $66 \%$ visited a massage therapist to relieve pain or muscular soreness and $45 \%$ sought massage to relieve stress. Thirty percent of clients incorporate massage into their injury rehabilitation strategy (Patrick, 2014). As suggested by ABMP (2009), the average duration of a massage is $1 \mathrm{~h}$. The majority (78.5\%) however is between 50 and $75 \mathrm{~min}$ in length. However, $10.3 \%$ of massages last longer than 75 min (Patrick, 2014). Shorter sessions are often found in situations such as chair massage in airports and other public venues. Given the length and number of massage treatments performed by therapists, one could expect health realities for massage therapists, including the development of osteoarthritic symptoms.

Osteoarthritis $(\mathrm{OA})$ is described as a degenerative form of arthritis that affects the smooth cartilage that covers the ends of bone, and is currently seen as the leading cause of musculoskeletal disability and pain amongst those 65 years and older (Flynn \& Ohnson, 2007, pp. 7-9; McKay, Prapavessis, \& NcNair, 2012; Sharma, 2006, p. 172; Vuolteenaho, Koskinen, \& Moilanen, 2013). OA is a debilitating condition that affects young and old alike (Flynn \& Ohnson, 2007, pp. 7-9). As OA progresses, the smooth cartilage at the ends of the bone are worn away, causing painful bone on bone friction. The hip joints, spine, knees, small bones of the fingers and the base of the thumbs are most commonly affected (Flynn \& Ohnson, 2007, pp. 7-9). Multiple risk factors in the development of OA have been established; these include age, sex, obesity, family history and occupation (Cimmino et al. 2013; Conaghan, Dickson, \& Grant, 2008; Prieto-Alhambra et al. 2014; Pun et al. 1994; Vuolteenaho et al. 2013).

Females are also at higher risk for developing OA (Jones, Cooley, \& Stankovich, 2002), and this risk further increases with age (Felson, 2004; McKay et al. 2012). Obesity was originally thought to contribute to OA by the load placed on weightbearing joints; however obesity has also been linked to OA in the hands (Cimmino et al. 2013). Leptin, an adipose-derived hormone, has been found to be increased in synovial or joint fluid of obese patients and has been linked with OA (Vuolteenaho et al. 2013). Genetic risk factors or genetic predisposition has been found to account for up to $65 \%$ of cases (Pun et al. 1994). Biomechanical risk factors such as occupational usage of joints, joint laxity and joint mal-alignment have also been implicated in the development of OA (Conaghan et al. 2008). The agricultural, construction, and mining sectors (O'Reilly, Muir, \& Doherty, 2000; Sandmark, Hogstedt, \& Vingard, 2000; Thelin, Vingard, \& Holmberg, 2004; Dillon, Petersen, \& Tanaka, 2002), housekeeping (Rossignol et al. 2005), the operation of machinery (O'Reilly et al. 2000), the clothing industry (O'Reilly et al. 2000) and physiotherapy (Snodgrass \& Rivett, 2002) have all been implicated in the contribution to the development of OA. The risk factors must not be mistaken for the cause of the condition. Two categories have been identified when evaluating the cause of OA. The primary group of causes are those that result in the breakdown of cartilage with movement or over time. The second category involves the initiation of OA due to joint injury or disease (Flynn \& Ohnson, 2007, pp. 7-9). All these factors could cause significant symptoms.

Symptoms are also specific and can be identified by the audible 'creaking' sounds whilst the joint is in motion and is often associated with pain (Flynn \& Ohnson, 2007, pp. 7-9). Joint swelling may be evident and may over time become permanent bony enlargements. The joint may also feel stiff when first waking in the morning (Flynn \& Ohnson, 2007, pp. 7-9). Muscle weakness and a decrease in joint range of movement are also observed (Cibulka \& Threlkeld, 2004). A recent study by Bernard and colleagues found that females experience painful jolting of the hands as a symptom of OA (Bernard, Wilder, Aluoch, \& Leaverton, 2010). Bellamy et al. (2002) found that OA sufferers have a marked difficulty with daily tasks such as peeling vegetables. Pain, stiffness and moving difficulties were the primary focus when evaluating female massage therapists. Persistent pain, limited morning 
stiffness and reduced function are three symptoms that have proved to be most useful in the diagnostic process (Zhang et al. 2010). The Centre for Disease Control (CDC) also classifies OA as symptomatic when pain, swelling and/or stiffness is experienced in the joint (CDC 2014).

Currently, OA is the leading cause of disability (Flynn \& Ohnson, 2007, pp. 7-9; McKay et al. 2012; Sharma, 2006, p. 172; Vuolteenaho et al. 2013) and has begun to affect the working class at ages as young as 40 years (Felson et al. 2000). Considering this, one would assume that statistics on the matter would be readily available. Furthermore, Mike Boddy, Chief Executive Officer of The Arthritis Foundation of South Africa (AFSA), stated in a personal conversation on December 5th, 2014 that there has been no survey conducted on the number of patients suffering from OA in South Africa. Furthermore, he advised that the Centre for Disease Control (CDC) in the United States (US) be consulted for their latest available statistics regarding the matter. The CDC statistics on arthritis in the US is as follows: based on the 2007-2009 data from the National Health Interview Survey (NHIS), an estimated 50 million (22\%) adults have doctor-diagnosed arthritis and 21 million (9\% of all adults) have arthritis and arthritisattributable activity limitation (Cheng, Hootman, Murphy, Langmaid, \& Helmick, 2010). Based on the 2003 NHIS data a projection of 67 million (25\%) adults aged 18 years or older will have doctor-diagnosed arthritis by the year 2030 and an estimated 37\% (25 million adults) of those with arthritis will report arthritis-attributable activity limitations by the year 2030 (Hootman \& Helmick, 2006). These statistics are unfortunately based on overall OA diagnosis and makes no special mention of specific joint involvement.

Data on the prevalence of symptomatic OA also remains limited (Prieto-Alhambra et al. 2014), and there is no data available on the prevalence of OA symptoms in massage therapists. As mentioned before, due to the stress and strain placed on the massage therapists hands on a daily basis, there may be a possible relationship between massage therapy as an occupation and the occurrence of premature osteoarthritic symptoms of the hands. Single incidences of strain acquired while performing a massage can accumulate into an overuse injury when repeated over days or months (Prichard, 2007, pp. 33-45). Awkward, physically stressful and/or repetitive movements, especially whilst applying pressure, may result in accumulative joint stress. Accumulative strain may cause permanent damage if persisted and left untreated. Permanent damage incurred may even cause one to abandon ones career (Prichard, 2007, pp. 33-45). In a study done by Page (2012) it was found that wrist and thumb pain was present among the therapists he studied.

How massage therapists are physically affected on a daily basis and in the long term by their profession has not been adequately addressed by the research community. Adequate investigation into the presence of OA symptoms amongst massage therapists may assist in developing strategies that could prolong the massage therapists' occupational lifetime. It may also help to promote good technique that may prevent injury.

\subsection{Objectives}

This study aimed to investigate the prevalence of selfreported OA symptoms of the hands amongst female massage therapists in South Africa, as well as to establish an average age of symptomatic onset and whether the symptoms were negatively influencing work productivity on a daily basis.

\section{Research methods and design}

\subsection{Research design}

A quantitative, descriptive and investigative research method, which incorporated the use of self-administered e-mail questionnaires.

\subsection{Population and sampling}

A total (male and female) of 160 massage therapists were registered with the Allied Health Professions Council of South Africa (AHPCSA) and the Massage Therapy Association of South Africa (MTASA) at the time of the study. The female to male representation was 133:27. Participation for this study was limited to females of any age, actively practicing as massage therapists. The main reasons for the selective sample was that according to research females have a higher risk of developing $\mathrm{OA}$ and the small number of registered males did not pose an accurate representation of the male massage community. As a massage therapist, it is not a professional requirement to be registered with a governing body in South Africa. There are many more massage therapists that are not registered than those that are. Registered massage therapists were chosen as the governing body could provide contact information regarding their members. This eased the search of an appropriate population. It is also widely accepted that therapists that are registered with a governing body are deemed to have adequate qualifications.

No restriction was placed on employment duration. Both persons with or without a family history of OA was included. Therapists with the following previously diagnosed conditions (as determined by the questionnaire) were excluded from the study: osteoporosis, rheumatoid arthritis, gout, Scleroderma, Lupus, Fibromyalgia, Carpel Tunnel Syndrome, Lyme disease, Ankylosing Spondylitis, infectious arthritis, reactive arthritis and joint dislocation at the time of the completion of the questionnaire. None of the participants indicated on the questionnaire that they had been diagnosed with any of these conditions.

As advised by statisticians at Statkon, UJ, a minimum of 50 participants were needed to maintain statistical validity and allow a fair representation of the population.

\subsection{Data collection}

Self-administered questionnaires with both open and closed ended questions were relied upon to gather information from a South African female population of registered massage therapists. Many of the massage therapists from the list provided by the AHPCSA were no longer registered. One hundred and two massage therapists of the 133 registered female therapists were contacted either via email or telephone; of which 89 requested the questionnaire. All participants consented and agreed to partake in the study by returning the 
questionnaire via email. Only 53 participants returned their questionnaires ( $n=53,40 \%$ response rate).

The self-administered questionnaire comprised of two main sections. The first section (open ended questions) aimed to establish the participant's demographics. This was achieved by asking questions such as age, average working years, average working days per week, average working hours per week, height and weight (to calculate participants' BMI), family history of OA, and prior hand joint injury. Participants were also required to indicate (from a list) if they had been previously diagnosed with certain diseases (as listed previously). Participants were also asked if they had any pain or stiffness in their hands, or difficulty with daily tasks, and whether they found that the presence thereof influenced their daily working productivity (Zhang et al., 2010). Section two (closed ended questions) comprised of the AUSCAN"M (Australian/Canadian) Hand Osteoarthritis Index LK3.1. This section consisted of three sub categories each assessing a different dimension of pain (sub-section A), stiffness (subsection $\mathrm{B}$ ), and difficulty performing daily tasks (sub-section C), by using a battery of 15 questions (Bellamy et al., 2002). The questions were answered on a 5 point Likert, $100 \mathrm{~mm}$ Visual Analogue Scale (VAS) ranging from 0 to $4(0=$ none, $1=$ mild, 2 = moderate, 3 = severe, 4 = extreme). A sub-score for each sub-section (A, B and C) was then calculated, and a total score for the entire AUSCAN ${ }^{\mathrm{TM}}$ was calculated by summation of the 3 sub-scores. The AUSCAN ${ }^{\mathrm{TM}}$ Osteoarthritis Index LK3.1 was used to identify and confirm the presence of osteoarthritic symptoms in the hands. This allowed the study to establish the prevalence of osteoarthritic symptoms in the hands among massage therapists. Those that received the questionnaire received their first reminder email one month after they received the questionnaire. Thereafter they received a reminder email every two weeks.

\subsection{Data analysis}

All data gathered was analysed by the statistics department (Statkon). The population size was 133 and sample size was 53 registered female massage therapists. Correlations were done between the variables, for example, between age and overall AUSCANTM Osteoarthritis Hand Index LK3.1 total. Correlations between symptomatic and non-symptomatic groups were not done.

These correlations were done using the overall sample, those that indicated the presence of possible OA symptoms, as well as those that did not indicate the presence of symptoms. Participants who indicated that they experienced osteoarthritic symptoms and gave an onset date and/or duration were divided into the symptomatic group. Those who did not provide an onset date were seen as the non-symptomatic group. By doing so it was possible to divide those who presented with self-reported symptoms from those who presented with no symptoms. This division was done under guidance of statisticians to establish adequate comparative data, as well as substantiate the presence of notable symptoms as participants reported symptoms even before answering the AUSCAN ${ }^{\mathrm{TM}}$ Osteoarthritis Hand Index LK3.1. The analysis constituted the frequencies and descriptive, testing for normality using the Kolmogorof-Smirnov and Shapiro-Wilk tests, and correlations between variables.

It is necessary to note that although 53 participants returned the questionnaire, some did not answer all the questions. This explains the difference in sample size for some of the questions. IBM SPSS Statistics software version 21 was used for statistical analysis.

\section{Results}

Participant demographics can be seen in Table 1. Forty nine $(\mathrm{n}=49)$ participants completed the questionnaire fully. In this study, participants had a mean age of 46.57 . When questioned on the age of symptomatic presentation, a mean age of 46.39 was calculated. The mean age and age of symptomatic presentation was older than expected. The mean age is however a positive outcome as age is a risk factor for OA, thus an older mean age may produce an increased prevalence of osteoarthritic symptoms. Participants were asked to give their height $(\mathrm{m})$ and weight $(\mathrm{kg})$. This was used to calculate their BMI, since an increased BMI has been linked to an increased risk of OA (Cimmino et al., 2013). The mean BMI was 24.15 (normal). Most of the participants presented with a BMI of between 20.31 (normal) and 27.99 (overweight). The mean amount of years in practice was calculated at 12.70 . On average, participants spent $21.54 \mathrm{~h}$ per week on massage. The majority of the participants spent between 9.14 and $33.94 \mathrm{~h}$ massaging a week. The maximum was a staggering $60 \mathrm{~h}$ per week. Participants were asked how many months/years had they been experiencing osteoarthritic symptoms in their hands (e.g. pain and stiffness of the joints). Twenty five $(\mathrm{n}=25)$ participants stated they had been experiencing such symptoms, with an average

Table 1 - Frequencies and descriptive analysis of participant demographics.

\begin{tabular}{|c|c|c|c|c|c|c|c|c|}
\hline & \multicolumn{2}{|c|}{$\mathrm{N}^{\mathrm{a}}$} & \multirow[t]{2}{*}{ Mean } & \multirow[t]{2}{*}{ Median } & \multirow[t]{2}{*}{ Mode } & \multirow[t]{2}{*}{ Std. dev } & \multirow[t]{2}{*}{$\operatorname{Min}^{c}$} & \multirow[t]{2}{*}{$\operatorname{Max}^{\mathrm{d}}$} \\
\hline & Valid & Missing & & & & & & \\
\hline Age & 51 & 1 & 46.57 & 46.00 & 55 & 12.11 & 26 & 73 \\
\hline Body mass index & 49 & 3 & 24.15 & 23.23 & 18.34 & 3.84 & 18.40 & 32.33 \\
\hline Working years as a massage therapist? & 51 & 1 & 12.70 & 12.00 & 10.00 & 6.78 & 1.00 & 31.00 \\
\hline Average hours per week spent massaging & 48 & 4 & 21.54 & 20.00 & 20.0 & 12.40 & 2.4 & 60.0 \\
\hline Age 1st noticed symptoms & 23 & 29 & 46.39 & 49.00 & 50 & 11.44 & 28 & 71 \\
\hline $\begin{array}{l}\text { a Sample number. } \\
\text { b Standard deviation. } \\
\text { c Minimum. } \\
\text { d Maximum. }\end{array}$ & & & & & & & & \\
\hline
\end{tabular}


of 3.74 years; 20 participants $(n=20)$ stated that they had not been experiencing any osteoarthritic-like symptoms.

Participants were asked if they had a family history of OA. If they answered yes, they were asked to give their relationship to the individual. Forty nine participants out of a total of $52(94.2 \%)$ answered this question, with 19 participants (36.5\%) stating that they had a family history of OA: $32.7 \%$ indicated they had a first generation family member (mother, father) with OA, while $3.8 \%$ of participants had a 2 nd generation (grandmother or aunt) family history of OA. When asked if participants had experienced prior joint injury such as dislocation or cartilage damage to their hands, $88.5 \%$ responded that they had not experienced such injury, while $11.5 \%$ had experienced prior hand joint injury.

Correlation studies between the AUSCAN" ${ }^{\mathrm{TM}}$ Hand Osteoarthritis Index LK3.1 and those participants that experienced prior hand joint injury was insignificant. This could be due to the small group of respondents that indicated such an injury. All participants were also asked if they felt that the pain and stiffness that they may be feeling in their hands negatively affected their work productivity on a daily basis. Only 41 participants $(n=41)$ answered this question. Twenty three (56.1\%) of these participants indicated that the symptoms did not affect their daily work productivity, while 11 (26.8\%) stated that the pain negatively impacted their work. A further three participants $(7.3 \%)$ stated that the pain felt in their hands sometimes impacted on their work; one participant $(2.4 \%)$ reported that the pain partially affected her work, and three $(7.3 \%)$ reported that the question was non-applicable.

\subsection{AUSCAN ${ }^{\mathrm{TM}}$ Osteoarthritis Hand Index LK3.1}

\subsubsection{Non-symptomatic group}

As mentioned participants who answered that they were not experiencing any pain or stiffness in their hands were allocated to the non-symptomatic group. This group comprised of 20 participants $(40.8 \%)$. Although participants were classified as non-symptomatic, some indicated mild to moderate levels of pain, stiffness and difficulty with daily tasks on the AUSCAN $^{\mathrm{TM}}$ Index (see Table 2). In Section A, participants were asked to think about their levels of pain when doing specific tasks over the last $48 \mathrm{~h}$. When evaluating the pain that they experienced whilst resting, 95\% indicated that they felt no pain, while $5 \%$ indicated a mild level of pain. With regards to the gripping or turning of objects, $5 \%$ experienced moderate pain.

Section B evaluated the stiffness that participants felt when first waking in the morning. In the non-symptomatic group, two participants (10\%) complained of mild stiffness. Section $\mathrm{C}$ evaluated the prevalence of degree of difficulty

Table 2 - AUSCAN osteoarthritis hand index for participants in the non-symptomatic group. Participants were asked to evaluate their symptoms during the last $48 \mathrm{~h}$.

\begin{tabular}{|c|c|c|c|c|c|c|c|}
\hline & & None & Mild & Moderate & Severe & Extreme & Total \\
\hline \multicolumn{8}{|l|}{ Section A (Pain) } \\
\hline \multirow[t]{2}{*}{ At rest } & Count & 19 & 1 & 0 & 0 & 0 & 20 \\
\hline & Row N \% & $95 \%$ & $5 \%$ & $0 \%$ & $0 \%$ & $0 \%$ & $100 \%$ \\
\hline \multirow[t]{2}{*}{ When gripping objects } & Count & 19 & 0 & 1 & 0 & 0 & 20 \\
\hline & Row N \% & $95 \%$ & $0 \%$ & $5 \%$ & $0 \%$ & $0 \%$ & $100 \%$ \\
\hline \multirow[t]{2}{*}{ When lifting objects } & Count & 20 & 0 & 0 & 0 & 0 & 20 \\
\hline & Row N \% & $100 \%$ & $0 \%$ & $0 \%$ & $0 \%$ & $0 \%$ & $100 \%$ \\
\hline \multirow[t]{2}{*}{ When turning objects } & Count & 19 & 0 & 1 & 0 & 0 & 20 \\
\hline & Row N \% & $95 \%$ & $0 \%$ & $5 \%$ & $0 \%$ & $0 \%$ & $100 \%$ \\
\hline \multirow[t]{2}{*}{ When squeezing objects } & Count & 20 & 0 & 0 & 0 & 0 & 20 \\
\hline & Row N \% & $100 \%$ & $0 \%$ & $0 \%$ & $0 \%$ & $0 \%$ & $100 \%$ \\
\hline \multicolumn{8}{|l|}{ Section B (Stiffness) } \\
\hline \multirow[t]{2}{*}{ How severe is stiffness after first wakening in the morning? } & Count & 18 & 2 & 0 & 0 & 0 & 20 \\
\hline & Row N \% & $90 \%$ & $10 \%$ & $0 \%$ & $0 \%$ & $0 \%$ & $100 \%$ \\
\hline \multicolumn{8}{|l|}{ Section C (Difficulty performing daily activities) } \\
\hline \multirow[t]{2}{*}{ Turning taps/faucets on } & Count & 20 & 0 & 0 & 0 & 0 & 20 \\
\hline & Row N \% & $100 \%$ & $0 \%$ & $0 \%$ & $0 \%$ & $0 \%$ & $100 \%$ \\
\hline \multirow[t]{2}{*}{ Turning a round doorknob or handle } & Count & 20 & 0 & 0 & 0 & 0 & 20 \\
\hline & Row N \% & $100 \%$ & $0 \%$ & $0 \%$ & $0 \%$ & $0 \%$ & $100 \%$ \\
\hline \multirow[t]{2}{*}{ Doing buttons } & Count & 20 & 0 & 0 & 0 & 0 & 20 \\
\hline & Row N \% & $100 \% \%$ & $0 \%$ & $0 \%$ & $0 \%$ & $0 \%$ & $100 \%$ \\
\hline \multirow[t]{2}{*}{ Fastening jewellery } & Count & 20 & 0 & 0 & 0 & 0 & 20 \\
\hline & Row N \% & $100 \%$ & $0 \%$ & $0 \%$ & $0 \%$ & $0 \%$ & $100 \%$ \\
\hline \multirow[t]{2}{*}{ Opening a new jar } & Count & 17 & 2 & 1 & 0 & 0 & 20 \\
\hline & Row N \% & $85 \%$ & $10 \%$ & $5 \%$ & $0 \%$ & $0 \%$ & $100 \%$ \\
\hline \multirow[t]{2}{*}{ Carrying a full pot with one hand } & Count & 19 & 0 & 0 & 0 & 0 & 19 \\
\hline & Row N \% & $100 \%$ & $0 \%$ & $0 \%$ & $0 \%$ & $0 \%$ & $100 \%$ \\
\hline \multirow[t]{2}{*}{ Peeling vegetables/fruit } & Count & 19 & 0 & 0 & 0 & 0 & 19 \\
\hline & Row N \% & $100 \%$ & $0 \%$ & $0 \%$ & $0 \%$ & $0 \%$ & $100 \%$ \\
\hline \multirow[t]{2}{*}{ Picking up large heavy objects } & Count & 19 & 0 & 0 & 0 & 0 & 19 \\
\hline & Row N \% & $100 \%$ & $0 \%$ & $0 \%$ & $0 \%$ & $0 \%$ & $100 \%$ \\
\hline \multirow[t]{2}{*}{ Wringing out wash cloths } & Count & 19 & 0 & 0 & 0 & 0 & 19 \\
\hline & Row N \% & $100 \%$ & $0 \%$ & $0 \%$ & $0 \%$ & $0 \%$ & $100 \%$ \\
\hline
\end{tabular}


whilst performing daily tasks and activities. Participants indicated that they did not experience any difficulty in performing most of the tasks/activities, except when opening a new jar, with $10 \%$ experiencing mild difficulty, and 5\% experiencing moderate difficulty.

\subsubsection{Symptomatic group}

Participants who answered that they were experiencing pain and or stiffness in their hands were placed into the symptomatic group (Table 3). This group comprised of 25 individuals $(\mathrm{n}=25)$, which was $51 \%$ of the entire group. Section A (pain evaluation) revealed that $60 \%$, or 15 symptomatic participants, experienced pain while at rest, with $44 \%(n=11)$ experiencing mild pain, and $16 \%(n=4)$ experiencing moderate pain. A total of $64 \%$ of symptomatic participants $(n=16)$ indicated pain when gripping objects, with nine participants (36\%) experiencing mild pain, and seven participants (28\%) experiencing moderate pain. Fifty six percent of symptomatic participants $(n=14)$ experienced pain in their hands when lifting objects; seven participants (28\%) experienced mild pain, six participants (24\%) felt moderate pain, and one participant (4\%) experienced severe pain. A total of $80 \%$ of symptomatic participants $(n=20)$ indicated they experienced pain when turning objects, with ten (40\%) experiencing mild pain, eight (32\%) experiencing moderate pain, and two (8\%) experiencing severe pain. When asked to report on the degree of pain felt when squeezing objects, $64 \%$ of symptomatic participants ( $n=16)$ felt pain; 11 (44\%) participants experienced mild pain, three (12\%) participants' experienced moderate pain, and two participants $(8 \%)$ reported severe pain.

Section B (stiffness) revealed that $64 \%$ of the symptomatic participants $(n=16)$ experienced stiffness when first waking in the morning. Eleven participants (44\%) indicated mild stiffness, two (8\%) indicated moderate stiffness and three (12\%) indicated severe stiffness.

Section C (degree of difficulty whilst performing daily tasks/ activities) indicated that $28 \%$ of symptomatic participants $(n=7)$ had some degree of difficulty when turning taps $(16 \%$ experienced mild difficulty, and $12 \%$ experienced moderate difficulty). When evaluating the difficulty in turning a round doorknob or handle, $20.8 \%$ of participants $(n=5)$ experienced a mild degree of difficulty, $4.2 \%(n=1)$ experienced moderate difficulty and $8.3 \%(n=2)$ experienced a severe degree of difficulty. Twenty eight percent of symptomatic participants $(n=7)$ indicated that they experienced mild difficulty with doing buttons and only $8 \%(n=2)$ indicated moderate difficulty.

A total of $28 \%$ of symptomatic participants $(n=7)$ had some degree of difficulty in the fastening of jewellery, with $16 \%$ $(\mathrm{n}=4)$ having mild difficulty, $8 \%(\mathrm{n}=2)$ having moderate difficulty, and $4 \%(n=1)$ having severe difficulty. When asked what degree of difficulty was experienced when opening a new jar, $80 \%$ of symptomatic participants $(n=20)$ stated that

Table 3 - AUSCANTM Osteoarthritis Hand Index for participants in the symptomatic group. Participants were asked to note their symptoms during the past $48 \mathrm{~h}$.

\begin{tabular}{|c|c|c|c|c|c|c|c|}
\hline & & None & Mild & Moderate & Severe & Extreme & Total \\
\hline \multicolumn{8}{|l|}{ Section A (Pain) } \\
\hline \multirow[t]{2}{*}{ At rest } & Count & 10 & 11 & 4 & 0 & 0 & 25 \\
\hline & Row N \% & $40 \%$ & $44 \%$ & $16 \%$ & $0 \%$ & $0 \%$ & $100 \%$ \\
\hline \multirow[t]{2}{*}{ When gripping objects } & Count & 9 & 9 & 7 & 0 & 0 & 25 \\
\hline & Row N \% & $36 \%$ & $36 \%$ & $28 \%$ & $0 \%$ & $0 \%$ & $100 \%$ \\
\hline \multirow[t]{2}{*}{ When lifting objects } & Count & 11 & 7 & 6 & 1 & 0 & 25 \\
\hline & Row N \% & $44 \%$ & $28 \%$ & $24 \%$ & $4 \%$ & $0 \%$ & $100 \%$ \\
\hline \multirow[t]{2}{*}{ When turning objects } & Count & 5 & 10 & 8 & 2 & 0 & 25 \\
\hline & Row N \% & $20 \%$ & $40 \%$ & $32 \%$ & $8 \%$ & $0 \%$ & $100 \%$ \\
\hline \multirow[t]{2}{*}{ When squeezing objects } & Count & 9 & 11 & 3 & 2 & 0 & 25 \\
\hline & Row N \% & $36 \%$ & $44 \%$ & $12 \%$ & $8 \%$ & $0 \%$ & $100 \%$ \\
\hline \multicolumn{8}{|l|}{ Section B (Stiffness) } \\
\hline \multirow{2}{*}{$\begin{array}{l}\text { How severe is stiffness after first wakening } \\
\text { in the morning? }\end{array}$} & Count & 9 & 11 & 2 & 3 & 0 & 25 \\
\hline & Row N \% & $36 \%$ & $44 \%$ & $8 \%$ & $12 \%$ & $0 \%$ & $100 \%$ \\
\hline \multicolumn{8}{|l|}{ Section C (Difficulty performing daily activities) } \\
\hline \multirow[t]{2}{*}{ Turning taps/faucets on } & Count & 18 & 4 & 3 & 0 & 0 & 25 \\
\hline & Row N \% & $72 \%$ & $16 \%$ & $12 \%$ & $0 \%$ & $0 \%$ & $100 \%$ \\
\hline \multirow[t]{2}{*}{ Turning a round doorknob or handle } & Count & 16 & 5 & 1 & 2 & 0 & 24 \\
\hline & Row N \% & $66.7 \%$ & $20.8 \%$ & $4.2 \%$ & $8.3 \%$ & $0 \%$ & $100 \%$ \\
\hline \multirow{2}{*}{ Doing buttons } & Count & 16 & 7 & 2 & 0 & 0 & 25 \\
\hline & Row N \% & $64 \%$ & $28 \%$ & $8 \%$ & $0 \%$ & $0 \%$ & $100 \%$ \\
\hline \multirow[t]{2}{*}{ Fastening jewellery } & Count & 18 & 4 & 2 & 1 & 0 & 25 \\
\hline & Row N \% & $72 \%$ & $16 \%$ & $8 \%$ & $4 \%$ & $0 \%$ & $100 \%$ \\
\hline \multirow[t]{2}{*}{ Opening a new jar } & Count & 5 & 8 & 10 & 1 & 1 & 25 \\
\hline & Row N \% & $20 \%$ & $32 \%$ & $40 \%$ & $4 \%$ & $4 \%$ & $100 \%$ \\
\hline \multirow[t]{2}{*}{ Carrying a full pot with one hand } & Count & 6 & 6 & 8 & 4 & 0 & 24 \\
\hline & Row N \% & $25 \%$ & $25 \%$ & $33.3 \%$ & $16.7 \%$ & $0 \%$ & $100 \%$ \\
\hline \multirow[t]{2}{*}{ Peeling vegetables/fruit } & Count & 19 & 6 & 0 & 0 & 0 & 25 \\
\hline & Row N \% & $76 \%$ & $24 \%$ & $0 \%$ & $0 \%$ & $0 \%$ & $100 \%$ \\
\hline \multirow[t]{2}{*}{ Picking up large heavy objects } & Count & 10 & 7 & 6 & 2 & 0 & 25 \\
\hline & Row N \% & $40 \%$ & $28 \%$ & $24 \%$ & $8 \%$ & $0 \%$ & $100 \%$ \\
\hline \multirow[t]{2}{*}{ Wringing out wash cloths } & Count & 8 & 7 & 7 & 3 & 0 & 25 \\
\hline & Row N \% & $32 \%$ & $28 \%$ & $28 \%$ & $12 \%$ & $0 \%$ & $100 \%$ \\
\hline
\end{tabular}


they experienced difficulty (32\% mild, $40 \%$ moderate, $4 \%$ severe and $4 \%$ extreme). Seventy five percent of participants in the symptomatic group $(n=18)$ had difficulty in carrying a full pot with one hand, with $25 \%$ experiencing mild difficulty $(\mathrm{n}=6), 33.3 \%$ experiencing moderate difficulty $(\mathrm{n}=8)$, and $16.7 \%$ experiencing severe difficulty $(n=4)$. Evaluating the difficulty with peeling vegetables/fruits revealed that only $24 \%$ of symptomatic participants $(n=6)$ experienced mild difficulty, with the other $76 \%$ experiencing no difficulty $(n=19)$. A total of $60 \%$ of symptomatic participants $(n=15)$ experienced difficulty in picking up large heavy objects (28\% mild, $24 \%$ moderate, and $8 \%$ severe). Sixty eight percent of participants $(\mathrm{n}=17)$ experience mild $(28 \%)$, moderate $(28 \%)$ and severe (12\%) difficulty in wringing out wash cloths. The sub-section and total scores for both the non-symptomatic and symptomatic group can be found in Table 4 .

\section{Ethical considerations}

This study received full ethical approval by the University of Johannesburg Academic Ethics Committee (AEC09-01-2013).

To ensure participant's anonymity and confidentiality each participant was assigned a number and referred to only by that number. The participants were made aware that they were free to withdraw from the study at any time without prejudice and were free to choose not to answer any particular question. Participation would also not lead to any personal or social harm. Participants were not requested or advised to stop or change prescribed medications. An explanation of the study and its aims were included in the questionnaire. It was made clear to participants that by completing the questionnaire they understood and consented to any information being utilised for this study. No data was collected without the participant's knowledge or permission. The questionnaires will be destroyed three years after the results of the study have been made known. Results of this study are available to participants on request.

\section{Validity and reliability}

The AUSCAN"M Osteoarthritis Hand Index is a valid, reliable and responsive measure of outcome. The index has been developed by Bellamy et al. in 2002, and subjected to a validation study, which have addressed issues such as reliability, stability and internal consistency. A study conducted by Allen, DeVellis, Renner, Kraus, and Jordan (2007) found that internal consistency for the AUSCANTM Osteoarthritis Hand Index total scale and subscales was high among the full study sample $(\mathrm{n}=1730)$ and all subgroups (Cronbach's alphas $=0.89-0.96)$. The responsiveness was evaluated and the questionnaire was benchmarked against age- and gender-specific population based normative values (Bellamy et al., 2002). The index was paid for and permission to make use of it for the purpose of the study was granted.

\section{Discussion}

Data on the prevalence of OA symptoms in specific professions in South Africa is lacking, and there is no data available on the prevalence of OA in massage therapists in the South African context. Since it is clear that massage therapy is used by many, and given the length of treatment one could expect health realities for massage therapists this study sought to determine the prevalence of OA symptoms in the hands of massage therapists practicing in South Africa. Fifty one percent of the tested sample presented with symptoms, which may suggest that massage therapy is having a slight negative effect on the massage therapists' hands.

Age and obesity has been linked to the development of OA (Cimmino et al. 2013; Prieto-Alhambra et al. 2014; Vuolteenaho et al., 2013). The mean age of the sample was 46.57 with an average of 12.7 years in the industry. This may indicate that young massage therapists are not entering the field or possibly not registering with a regulating body. It is also possible that these persons pursued a different occupation prior to entering the field of massage therapy. A correlation was however found between age and the AUSCAN Index total $(p=0.047)$ which confirms that age is a risk factor for the development of OA symptoms. Twenty eight participants $(57.14 \%)$ presented with a normal BMI, while 20 participants (40.81\%) had a BMI above normal. The mean BMI was 24.15 (normal) and it showed no correlation to the totals for Section A, Section B, Section C or the overall AUSCAN"M Hand Osteoarthritis Index questionnaire. The p-values were: $0.332,0.851,0.703$ and 0.868 respectively. It may be assumed that the BMI did not have an

Table 4 - Sub-section and total scores for the AUSCAN ${ }^{\mathrm{TM}}$ Osteoarthritis Hand Index for both the non-symptomatic and symptomatic groups.

\begin{tabular}{|c|c|c|c|c|c|c|c|c|}
\hline & \multicolumn{2}{|c|}{$\mathrm{N}$} & \multirow[t]{2}{*}{ Mean } & \multirow[t]{2}{*}{ Median } & \multirow[t]{2}{*}{ Mode } & \multirow[t]{2}{*}{ Std. deviation } & \multirow[t]{2}{*}{ Minimum } & \multirow[t]{2}{*}{ Maximum } \\
\hline & Valid & Missing & & & & & & \\
\hline \multicolumn{9}{|c|}{ Non-symptomatic group } \\
\hline Section A & 20 & 0 & 0.25 & 0.00 & 0 & 1.118 & 0 & 5 \\
\hline Section B & 20 & 0 & 0.05 & 0.00 & 0 & 0.224 & 0 & 1 \\
\hline Section C & 19 & 1 & 0.16 & 0.00 & 0 & 0.501 & 0 & 2 \\
\hline Total score overall & 19 & 1 & 0.47 & 0.00 & 0 & 1.611 & 0 & 7 \\
\hline \multicolumn{9}{|l|}{ Symptomatic group } \\
\hline Section A & 25 & 0 & 4.68 & 5.00 & 0 & 3.816 & 0 & 12 \\
\hline Section B & 25 & 0 & 0.96 & 1.00 & 1 & 0.978 & 0 & 3 \\
\hline Section C & 25 & 0 & 6.96 & 4.00 & 2 & 5.653 & 0 & 21 \\
\hline Total score overall & 25 & 0 & 12.68 & 9.00 & 7 & 9.077 & 0 & 34 \\
\hline
\end{tabular}


influence on the overall score for the AUSCAN ${ }^{\mathrm{TM}}$ Hand Osteoarthritis Index questionnaire. This is contradictory to the literature which found that obesity increases your risk of hand OA (Vuolteenaho et al. 2013; Wen et al. 2016).

Participants were also asked at what age they first noticed any pain, stiffness and/or moving difficulties of their hands, and for how many years they had been experiencing osteoarthritic symptoms. The mean age reported by the 23 (44.23\%) participants $(n=23)$ who responded to this question was 46 years, with a mean duration of 3.74 years. There was a correlation between age and the AUSCAN ${ }^{\mathrm{TM}}$ Osteoarthritis Hand Index $(p=0.047)$. This suggests that participants are presenting with symptoms at an age that correlates with studies evaluating onset age in other professions (Felson et al., 2000). The youngest participant that indicated the presence of symptoms was 28 years old. The age of 50 had the highest repetitions followed by the age of 34, 54 and 59 presenting in equal numbers. Literature suggests that the risk for developing OA increases over the age of 50 (Rossignol et al. 2005). This study supports those five findings and it has shown that massage therapists may be developing symptoms before this age.

The average amount of hours worked per week by massage therapists was 21.54 (with a maximum of $60 \mathrm{~h}$ ), and there was no correlation between the amount of hours worked and the AUSCAN"M Osteoarthritis Hand Index ( $p=0.895)$. This finding was unexpected as it logically follows that with long working hours one would expect to find a greater prevalence of OA symptoms. Literature also suggests that prior joint dislocation or injury accounts for a high prevalence of OA (Lawrence et al. 2008). The majority of participants in this study (88.5\%) did not have any prior joint dislocation or injury.

A family history of OA may be a contributing factor in the development of OA (Hämäläinen et al. 2014). A portion of the participants (32.7\%) indicated that they had a first generation (mother, father) family member with OA, while $3.8 \%$ of the participants had a second generation (grandmother or aunt) family member with OA. Correlation studies could not be completed as the group was too small to yield a reliable correlation coefficient.

For evaluation of the AUSCANTM Osteoarthritis Hand Index, participants were divided into two groups, symptomatic and non-symptomatic, based on whether or not they indicated that they were experiencing osteoarthritic symptoms (age of onset and duration). Twenty participants $(n=20)$ indicated that they were not experiencing symptoms (non-symptomatic group). Despite this, some participants in this group reported that they felt mild to moderate pain and stiffness in their hands, and had some difficulty in performing certain daily tasks. Five point two six percent (5.26) of participants experienced pain at rest, stiffness when first waking in the morning as well as difficulty with gripping objects. Seventeen point six four percent (17.64\%) of non-symptomatic participants reported difficulty with opening a new jar. Although these participants did not report an age of symptomatic onset or a symptomatic duration, it is still evident that they are experiencing symptoms, however insignificant they may be. More than half of the participants ( $n=29$ ) were placed into the symptomatic group. A large portion of the symptomatic participants experienced osteoarthritic symptoms while at rest. Sixty percent of these participants indicated that they had mild to moderate pain in their hands, and 64\% experienced stiffness after first waking in the morning. Participants had more difficulty in performing daily tasks and activities that required more strength and mild to extreme difficulty in performing finer tasks.

The total score for the AUSCAN"M Osteoarthritis Hand Index for the non-symptomatic group was low, with a score of 0.47 out of a possible 60 . Thus very few of these participants did indeed show symptoms of possible OA. The symptomatic group had a higher total average score of 12.68 , with a maximum of 36 . This indicates that there is a definite presence of osteoarthritic symptoms among these therapists, and further research into the progression of these symptoms over time would provide valuable insights into the influence of massage therapy as an occupation on osteoarthritic symptoms.

\section{Limitations}

The greatest limitation to this study was the small sample size; this hindered adequate correlations and did not provide a great enough representation of the population. In retrospect the division of participants into symptomatic and nonsymptomatic groups could be seen as a limitation. Although it was originally done to enhance statistical comparison, it caused an overabundance of statistics that needed to be analysed that did not contribute to the outcome of the study.

\section{Recommendations}

A follow-up study on these participants would be of interest, and may indicate whether or not the symptoms have progressed with time. It is highly recommended that future studies incorporate massage therapists that are not registered. This may secure a greater sample size producing stronger correlations. Future studies may also include males. This would allow evaluation of the sex risk factor within the profession of massage therapy.

\section{Conclusion}

Massage therapy is one of the oldest practices, evolving over time into not only an alternative therapy, but also as a medium to support conventional medicine. It is currently in high demand all over the word as Western medicine is starting to recognise, once more, the numerous benefits such as stress relief, pain relief and rehabilitation (Patrick, 2014). Massage therapists are almost all self-employed, rely heavily on their hands and may be subject to loss of income due to the inability to practice. Research conducted on massage therapists and the occupational risk factors that they are exposed to are, as mentioned, limited. However, there is general consensus that practicing as a massage therapist, among other occupations, my increase the risk for developing numerous health problems such as cumulative joint strain and lower back and shoulder ailments (Casanelia \& Stelfox, 2010; Jang, Chi, Tsauo, \& Wang, 2006; Page, 2012; Prichard, 2007, , pp. 33-45; Wayne, Currie-Jackson, \& Duncan, 2008). 
More than $50 \%$ of participants in this study indicated that they were experiencing pain and stiffness in their hands and the AUSCAN ${ }^{\text {TM }}$ Osteoarthritis Hand Index confirmed these symptoms, with participants experiencing mild to moderate pain and stiffness, and mild to severe difficulty in performing daily tasks and activities.

This study has shown that massage therapists are experiencing osteoarthritic-like symptoms in their hands. However there was no correlation between the amount of hours worked per week, or the number of years in the profession. There is a need for future studies into the diagnosis of OA in massage therapists, as well as other conditions that may be influencing massage therapist's health and productivity. The practice of massage is an age old tradition and it is integral that it is preserved. Furthermore, it is of importance that the massage therapist's general health is considered in this fast growing industry. The industry must understand that without the therapist there is no therapy.

One may no longer assume that OA is a condition that only affects the elderly. OA has become one of the leading causes of disability and persons are falling victim to it at a younger age (Rossignol et al. 2005). In this study, the mean age of symptomatic presentation indicated that participants were presenting with OA-like symptoms in their hands at an earlier age than what was suggested in literature.

In conclusion, this study highlights the fact that female massage therapists in South Africa experience difficulty with daily tasks perhaps due to the repetitive strain on their hands, incurred by their chosen profession. Although a small sample, this study serves as basis for further dialogue, research and professional awareness. There is a clear indication that massage therapists may be at risk of developing OA of the hands; however this needs to be confirmed in a larger population. This study may foster further studies that specifically identify which elements of the profession are most harmful to the therapist. It may also motivate studies investigating other joint conditions that may be induced by the practice of massage.

\section{Author's contributions}

Miss H Kruger, who compiled this study as a requirement for her master's degree, was responsible for sourcing participants, collecting data as well as writing the manuscript and all associated adaptations. Dr N. Houreld was the supervisor assigned to this study and contributed significant academic guidance. Ms. V. Khumalo was assigned as the co-supervisor and acted as a liaison between the student and the Department of Somatology, Faculty of Heath Sciences at the University of Johannesburg.

\section{Acknowledgements}

The authors would like to acknowledge the massage therapists that participated in this study.

\section{R E F E R E N C E S}

Allen, K. D., DeVellis, R. F., Renner, J. B., Kraus, V. B., \& Jordan, J. M. (2007). Validity and factor structure of the AUSCAN Osteoarthritis Hand Index in a community-based sample. Osteoarthritis Cartilage, 15(7), 830-836.

Bureau of Labor Statistics, U.S. Department of Labor, Occupational Outlook Handbook, 2016-17 Edition, Massage Therapists, 2017, viewed 02 February 2017 http://www.bls.gov/ ooh/healthcare/massage-therapists.htm.

Bellamy, N., Campbell, J., Haraoui, B., Gerecz-Simon, E., Buchbinder, R., Hobby, K., et al. (2002). Clinimetric properties of the AUSCAN Osteoarthritis Hand Index: An evaluation of reliability, validity and responsiveness. Osteoarthritis and Cartilage, 10(11), 863-869.

Bernard, T. E., Wilder, F. V., Aluoch, M., \& Leaverton, P. E. (2010). Job related osteoarthritis of the knee, foot, hand and cervical spine. Journal of Occupational and Environmental Medicine, 52(1), 33-38.

Boddy, M. (2014). email, 5 December, mike@arthritis.org .

Braun, M. B., \& Simonson, S. (2008). Introduction to massage therapy (2nd ed.). Philadelphia, PA: Lippincott Williams and Wilkins.

Casanelia, L., \& Stelfox, D. (2010). Foundations of massage (3rd ed.). Australia: Churchill Livingstone.

Centre for Disease Control and Prevention. (2014). Osteoarthritis. viewed 18 November 2014, from http://www.cdc.gov/arthritis/ basics/osteoarthritis.htm.

Cheng, Y. J., Hootman, J. M., Murphy, L. B., Langmaid, G. A., \& Helmick, C. G. (2010). Prevalence of doctor-diagnosed arthritis and arthritis-attributable activity limitation - United States, 2007-2009. Morbidity and Mortality Weekly Report (MMWR), 59(39), 1261-1265.

Cibulka, M. T., \& Threlkeld, J. (2004). The early clinical diagnosis of osteoarthritis of the hip. The Journal of Orthopaedic and Sports Physical Therapy, 34(8), 461-467.

Cimmino, M. A., Scarpa, R., Caporali, R., Parazzini, F., Zaninelli, A., \& Sarzi-Puttini, P. (2013). Body mass and osteoarthritic pain: Results from a study in general practice. Clinical and Experimental Rheumatology, 31(6), 843-849.

Conaghan, P. G., Dickson, J., \& Grant, R. L. (2008). Care and management of osteoarthritis in adults: Summary of NICE guidance. British Medical Journal, 336(7642), 502-503.

Dillon, C., Petersen, M., \& Tanaka, S. (2002). Self-reported hand and wrist arthritis and occupation: Data from the U.S. National Health Interview Survey-occupational health supplement. American Journal of Independent Medicine, 42(4), 318-327.

Felson, D. T. (2004). Risk factors for osteoarthritis: Understanding joint vulnerability. Clinical Orthopaedics and Related Research, 427, 16-21.

Felson, D. T., Lawrence, R. C., Dieppe, P. A., Hirsch, R., Helmick, C. G., Jordan, J. M., et al. (2000). Osteoarthritis: New insights part I. The disease and its risk factors. Annals of Internal Medicine, 133(8), 635-646.

Flynn, J. A., \& Ohnson, T. (2007). John Hopkins white Papers: Arthritis. Baltimore: John Hopkins Medicine.

Hämäläinen, S., Solovieva, S., Vehmas, T., Luoma, K., LeinoArjas, P., \& Hirvonen, A. (2014). Genetic influences on hand osteoarthritis in Finnish women - a replication study of candidate genes. Plos One, 9(5). viewed on 24 October 2014, from http://dx.doi.org/10.1371/journal.pone.0097417.

Hootman, J. M., \& Helmick, C. G. (2006). Projections of U.S. prevalence of arthritis and associated activity limitations. Arthritis \& Rheumatism, 54(1), 266-229. 
Jang, Y., Chi, C. F., Tsauo, J. Y., \& Wang, J. D. (2006). Prevalence and risk factors of work, Related musculoskeletal disorders in massage practitioners. Journal of Occupational Rehabilitation, 16, 425-438.

Jones, G., Cooley, H. M., \& Stankovich, J. M. (2002). A cross sectional study of the association between sex, smoking, and other lifestyle factors and osteoarthritis of the hand. Journal of Rheumatology, 29(8), 1719-1724.

Lawrence, R. C., Felson, D. T., Helmick, C. G., Arnold, L. M., Choi, H., Deyo, R. A., et al. (2008). Estimates of the prevalence of arthritis and other rheumatic conditions in the United States. Part II. Arthritis \& Rheumatism, 58(1), 26-35.

McKay, C., Prapavessis, H., \& NcNair, P. (2012). Comparing the lower limb tasks questionnaire to the western Ontario and McMaster Universities Osteoarthritis Index: Agreement, responsiveness, and convergence with physical performance for knee osteoarthritis patients. Archives of Physical Medicine and Rehabilitation, 49(3), 474-479.

O'Reilly, S. C., Muir, K. R., \& Doherty, M. (2000). Occupation and knee pain: A community study. Osteoarthritis Cartilage, 8, 78-81.

Page, L. T. (2012). Licenced massage therapists strain index. Human Factors and Ergonomics Society, 56(1), 1163-1167.

Patrick, C. (2014). 'Massage profession metrics', in associated Bodywork \& massage professionals. viewed 18 November 2014 from http://www.massagetherapy.com/media/metrics_ massage_clients.php.

Prichard, D. (2007). Dynamic body use for effective strain free massage (pp. 33-45). California: North Atlantic Books.

Prieto-Alhambra, D., Judge, A., Javaid, M. K., Cooper, C., DiezPerez, A., \& Arden, N. K. (2014). Incidence and risk factors for clinically diagnosed knee, hip and hand osteoarthritis: Influence of age, gender and osteoarthritis affecting other joints. Annals of Rheumatic Disease, 73(9), 1659-1664.

Pun, Y. L., Moskowitz, R. W., Lie, S., Sundstrom, W. R., Block, S. R., Mcewen, C., et al. (1994). Clinical correlations of osteoarthritis associated with a single-base mutation (arginine 519 to cysteine) in type II procollagen gene. Arthritis \& Rheumatism, 37(2), 264-269.

Rossignol, M., Leclerc, A., Allaert, F. A., Rozenberg, S., Valat, J.-P., Avouac, B., et al. (2005). Primary osteoarthritis of hip, knee and hand in relation to occupational exposure. Occupational \& Environmental Medicine, 62(11), 772-777.

Sandmark, H., Hogstedt, C., \& Vingard, E. (2000). Primary osteoarthrosis of the knee in men and women as a result of lifelong physical load from work. Scandinavian Journal of Work, Environment \& Health, 26, 20-25.

Sharma, R. (2006). Common diseases and cure (p. 172). New Delhi: Lotus Press.

Snodgrass, S., \& Rivett, D. (2002). Thumb pain and physiotherapists: Potential risk factors and proposed prevention strategies. Journal of Manual and Manipulative Therapy, 10(4), 206-217.

Thelin, A., Vingard, E., \& Holmberg, S. (2004). Osteoarthritis of the hip joint and farm work. American Journal of Independent Medicine, 45, 202-209.

Vuolteenaho, K., Koskinen, A., \& Moilanen, E. (2013). Leptin - a link between obesity and osteoarthritis. Applications for prevention and treatment. Basic and Clinical Pharmacology and Toxicology, 114(1), 103-108.

Wayne, J. A., Currie-Jackson, N., \& Duncan, C. A. (2008). A survey of musculoskeletal injuries among Canadian massage therapists. Journal of Bodywork and Movement Therapies, 12(1), 86-93.

Wen, L., Kang, J. H., Yim, Y. R., Kim, J. E., Lee, J. W., Lee, K. E., et al. (2016). Associations between body composition measurements of obesity and radiographic osteoarthritis in older adults: Data from the Dong-gu study. BMC Musculoskeletal Disorders, 17(1), 192. http://dx.doi.org/10.1186/s12891-016-1040-9.

Zhang, W., Doherty, M., Peat, G., Bierma-Zeinstra, M. A., Arden, N. K., Bresnihan, B., et al. (2010). EULAR evidence based recommendations for the diagnosis of knee osteoarthritis. Annals of Rheumatic Disease, 69(3), 483-489. 